\title{
METALLURGY
}

DOI https://doi.org/10.30525/978-9934-588-79-2-1.36

\section{ТЕРМОДИНИМІЧНИЙ АНАЛІЗ ВІДНОВЛЕННЯ ОКСИДУ ХРОМУ ЙОГО ВИЩІМ КАРБІДОМ}

\author{
Гришин О. М. \\ кандидат технічних наук, дочент, \\ дочент кафедри теорії металургійних процесів і хімії \\ Національної металургійної академії України

\section{Петренко В. О.} \\ доктор технічних наук, професор, \\ професор кафедри інтелектуальної власності \\ Національної металургійної академії України \\ м. Дніпро, Україна
}

Відновлення оксиду хрому вищим карбідом останнього може бути описана реакцією:

$$
1 / 3 \mathrm{Cr}_{2} \mathrm{O}_{3}+9 / 5 \mathrm{Cr}_{3} \mathrm{C}_{2}=13 / 15 \mathrm{Cr}_{7} \mathrm{C}_{3}+\mathrm{CO}
$$

Незалежно від дійсного механізму, іiі термодинамічний аналіз доцільно здійснювати на основі двох реакцій:

$$
\begin{array}{cc|l}
+1 & 1 / 3 \mathrm{Cr}_{2} \mathrm{O}_{3}+11 / 7 \mathrm{CO}=2 / 21 \mathrm{Cr}_{7} \mathrm{C}_{3}+9 / 7 \mathrm{CO}_{2} \\
+9 / 7 & 7 & 5 \mathrm{Cr}_{3} \mathrm{C}_{2}+\mathrm{CO}_{2}=3 / 5 \mathrm{Cr}_{7} \mathrm{C}_{3}+2 \mathrm{CO} \\
\hline \Sigma & 1 & 3 \mathrm{Cr}_{2} \mathrm{O}_{3}+9 / 5 \mathrm{Cr}_{3} \mathrm{C}_{2}=13 / 15 \mathrm{Cr}_{7} \mathrm{C}_{3}+\mathrm{CO}
\end{array}
$$

Температурна залежність константи рівноваги реакції (2) була отримана за допомогою термохімічних даних [1]: Ln K = 22270 / T + $20.283(4)$

Для розрахунку рівноважного складу газової фази використовувалося рівняння:

$$
\begin{gathered}
\% \mathrm{CO}=50 \cdot \frac{\mathrm{K}}{\mathrm{P}} \cdot\left[\sqrt{1+\frac{4 \mathrm{P}}{\mathrm{K}}}-1\right] ; \% \mathrm{CO}_{2}=100-\% \mathrm{CO} \text { i } \mathrm{Ln} \mathrm{K}= \\
=-3232.9 / \mathrm{T}-5.7857
\end{gathered}
$$


Якщо $\mathrm{P}_{\mathrm{CO} 2}=\mathrm{X}$, то отримаємо рівняння:

$$
\mathrm{y}=\mathrm{X}^{9 / 11}+\mathrm{K}^{7 / 11} \cdot \mathrm{X}-\mathrm{K}^{7 / 11} \cdot \mathrm{P}=0
$$

Проведено аналіз також реакція:

$$
23 / 27 \mathrm{Cr}_{7} \mathrm{C}_{3}+\mathrm{CO}_{2}=7 / 27 \mathrm{Cr}_{23} \mathrm{C}_{6}+2 \mathrm{CO}
$$

Рівноважний склад газової фази розраховували за формулою (5). Розрахункові дані для всіх трьох реакцій графічно ілюструється рисунок 1. Аналіз їх свідчить про те, що відновлення $\mathrm{Cr}_{2} \mathrm{O}_{3}$ карбідом $\mathrm{Cr}_{3} \mathrm{C}_{2}$ стає термодинамічно можливим при $\sim 1300^{\circ} \mathrm{C}$. Це близько до розрахункової величини: $\mathrm{T}_{\mathrm{H}}=1287^{\circ} \mathrm{C}$; використання термохімічних відомос-

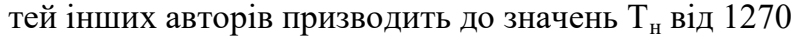

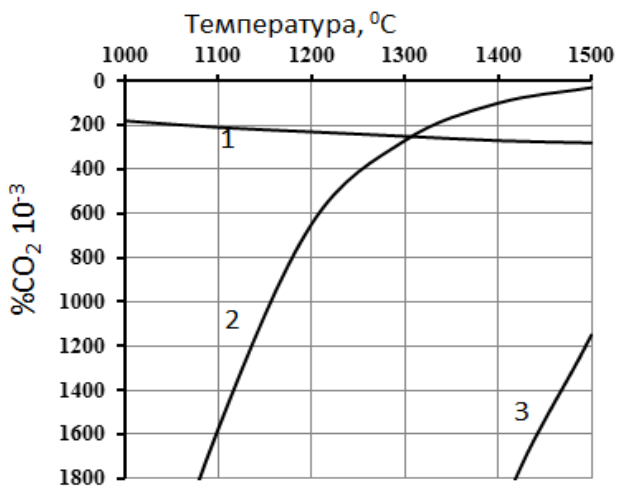

\section{Рис. 1. Рівноважний склад газової фази в реакціях відновлення} $\mathrm{Cr}_{2} \mathrm{O}_{3}(1)$ і газифікації карбідів хрому $(2,3)$

до $1283^{\circ} \mathrm{C}$ [2, с. 11]. Відновлення $\mathrm{Cr}_{2} \mathrm{O}_{3}$ за рахунок карбіду $\mathrm{Cr}_{7} \mathrm{C}_{3}$ в розглянутому температурному діапазоні і $\mathrm{P}=1$ неможливо. При подачі в реактор водню число можливих реакцій значно зростає. Необхідно, зокрема, враховувати взаємодію карбіду $\mathrm{Cr}_{3} \mathrm{C}_{2} 3$ водяною парою:

$$
7 / 5 \mathrm{Cr}_{3} \mathrm{C}_{2}+\mathrm{H}_{2} \mathrm{O}=3 / 5 \mathrm{Cr}_{7} \mathrm{C}_{3}+\mathrm{CO}+\mathrm{H}_{2}
$$

Константа рівноваги цієї реакції має вигляд:

$$
\mathrm{K}=\frac{\mathrm{P}_{\mathrm{H}_{2}} \cdot \mathrm{P}_{\mathrm{CO}}}{\mathrm{P}_{\mathrm{H}_{2} \mathrm{O}}}=\frac{\left(\% \mathrm{H}_{2}\right) \cdot(\% \mathrm{CO})}{\left(\% \mathrm{H}_{2} \mathrm{O}\right)} \cdot \frac{\mathrm{P}}{100} ; \quad \operatorname{lnK}=-\frac{18243.6}{\mathrm{~T}}+16.8254
$$

Позначивши \% $\mathrm{H}_{2} \mathrm{O}=\mathrm{X}, \% \mathrm{H}_{2}=\% \mathrm{CO}=(100-\mathrm{X}) / 2$, можна записати 
$\mathrm{P} \cdot \mathrm{X}^{2}-2 \cdot 10^{2}(2 \mathrm{~K}+\mathrm{P}) \mathrm{X}+10^{4} \mathrm{P}=0 ; \mathrm{X}=100 \cdot \frac{(2 \mathrm{~K}+\mathrm{P})-2 \mathrm{~K} \sqrt{1+\mathrm{P} / \mathrm{K}}}{\mathrm{P}}$

Рівноважний склад газової фази, представлене на рисунку 2. Видно, що взаємодія $\mathrm{Cr}_{3} \mathrm{C}_{2} 3 \mathrm{H}_{2} \mathrm{O}$ має суттєві термодинамічні переваги перед його реакцією з $\mathrm{CO}_{2}$. Були перевірені також умови, необхідні для розвитку реакції:

$$
\begin{gathered}
7 / 5 \mathrm{Cr}_{3} \mathrm{C}_{2}+2 \mathrm{H}_{2} \mathrm{O}=3 / 5 \mathrm{Cr}_{7} \mathrm{C}_{3}+2 \mathrm{H}_{2}+\mathrm{CO}_{2} \\
\mathrm{~K}=\frac{\mathrm{P}_{\mathrm{H}_{2}}^{2} \cdot \mathrm{P}_{\mathrm{CO}_{2}}}{\mathrm{P}_{\mathrm{H}_{2} \mathrm{O}}^{2}}=\frac{\left(\% \mathrm{H}_{2}\right)^{2} \cdot\left(\% \mathrm{CO}_{2}\right)}{\left(\% \mathrm{H}_{2} \mathrm{O}\right)^{2}} \cdot \frac{\mathrm{P}}{100} ; \quad \operatorname{lnK}=-\frac{14217.4}{\mathrm{~T}}+13.2169
\end{gathered}
$$

Позначивши $\% \mathrm{CO}_{2}=\mathrm{X} ; \% \mathrm{H}_{2}=2 \mathrm{X}$ i \% $\mathrm{H}_{2} \mathrm{O}=100-3 \mathrm{X}$, отримаємо рівняння для розрахунку рівноважного складу газової фази:

$$
\mathrm{K}=\frac{(2 \mathrm{X})^{2} \cdot \mathrm{X}}{(100-3 \mathrm{X})^{2}} \cdot \frac{\mathrm{P}}{100} ; \mathrm{y}=4 \mathrm{PX}^{3}-9 \cdot 10^{2} \cdot \mathrm{K} \cdot \mathrm{X}^{2}+6 \cdot 10^{4} \cdot \mathrm{K} \cdot \mathrm{X}-10^{6} \cdot \mathrm{K}
$$

Розрахунок показав, що рівноважна концентрація водяної пари багаторазово вище, ніж в реакції (2). При $1300-1400^{\circ} \mathrm{C}$ ця різниця перевищує два порядки.

Отже, реакція (10) не отримує в процесі відновлення $\mathrm{Cr}_{2} \mathrm{O}_{3}$ свого розвитку.

Було встановлено, що термодинамічно у визначених умовах неможливо реакція:

$$
23 / 27 \mathrm{Cr}_{7} \mathrm{C}_{3}+\mathrm{H}_{2} \mathrm{O}=7 / 27 \mathrm{Cr}_{23} \mathrm{C}_{6}+\mathrm{H}_{2}+\mathrm{CO}
$$

Комплексне відновлення оксиду хрому за участю водню має супроводжуватися реакцією:

$$
1 / 3 \mathrm{Cr}_{2} \mathrm{O}_{3}+\mathrm{H}_{2}=2 / 3 \mathrm{Cr}+\mathrm{H}_{2} \mathrm{O}
$$

Однак існування металевого хрому в умовах значних величин $\mathrm{P}_{\mathrm{CO}}$ при температурах до $1500^{\circ} \mathrm{C}$ стає неможливим. Поява вищого карбіду хрому за рахунок $\mathrm{CO}$ описується реакцією:

$$
3 / 2 \mathrm{Cr}+2 \mathrm{CO}=1 / 3 \mathrm{Cr}_{3} \mathrm{C}_{2}+\mathrm{CO}_{2}
$$




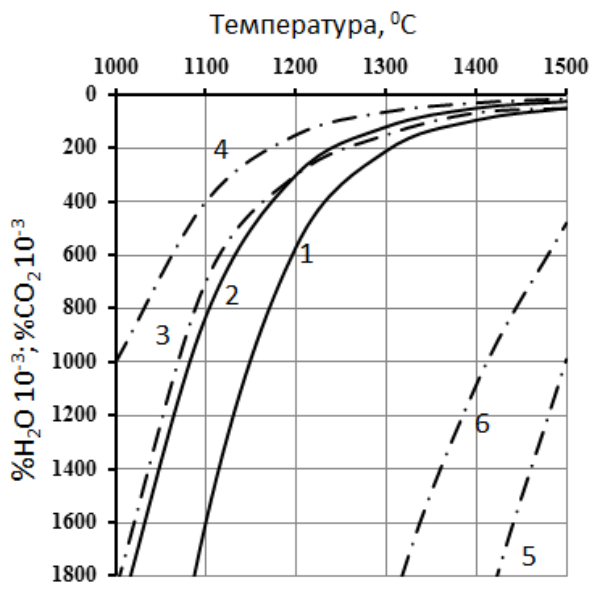

Рис. 2 Рівноважний склад газовой фази для реакций газифікації $\mathrm{Cr}_{3} \mathrm{C}_{2}$ при тиску 1 атм. $-1,3,5 ;$ i 0.5 атм. $-2,4,6$.

$$
\begin{gathered}
1-7 / 5 \mathrm{Cr}_{3} \mathrm{C}_{2}+\mathrm{CO}_{2}=3 / 5 \mathrm{Cr}_{7} \mathrm{C}_{3}+2 \mathrm{CO} ; \\
2-7 / 5 \mathrm{Cr}_{3} \mathrm{C}_{2}+\mathrm{CO}_{2}=3 / 5 \mathrm{Cr}_{7} \mathrm{C}_{3}+2 \mathrm{CO} ; \\
3-7 / 5 \mathrm{Cr}_{3} \mathrm{C}_{2}+\mathrm{H}_{2} \mathrm{O}=3 / 5 \mathrm{Cr}_{7} \mathrm{C}_{3}+\mathrm{H}_{2}+\mathrm{CO} ; \\
4-7 / 5 \mathrm{Cr}_{3} \mathrm{C}_{2}+\mathrm{H}_{2} \mathrm{O}=3 / 5 \mathrm{Cr}_{7} \mathrm{C}_{3}+\mathrm{H}_{2}+\mathrm{CO} ; \\
5-23 / 27 \mathrm{Cr}_{7} \mathrm{C}_{3}+\mathrm{H}_{2} \mathrm{O}=7 / 27 \mathrm{Cr}_{23} \mathrm{C}_{6}+\mathrm{H}_{2}+\mathrm{CO} ; \\
6-23 / 27 \mathrm{Cr}_{7} \mathrm{C}_{3}+\mathrm{H}_{2} \mathrm{O}=7 / 27 \mathrm{Cr}_{23} \mathrm{C}_{6}+\mathrm{H}_{2}+\mathrm{CO} .
\end{gathered}
$$

Рівноважний склад газової фази реакції (14), який визначимо по вже використаному вище алгоритмом, представлені на рисунку 3. Аналогічно було виконано розрахунок рівноваги для реакції:

$$
7 / 3 \mathrm{Cr}+2 \mathrm{CO}=1 / 3 \mathrm{Cr}_{7} \mathrm{C}_{3}+\mathrm{CO}_{2}
$$

Результати розрахунку представлені на рисунку 3 . Тут же показаний рівноважний склад газу для реакції (3), яка протікає відносно швидко і контролює склад газової фази. Зіставлення даних рисунку 3 дозволяє зробити висновок, що металевий хром, з'являється згідно реакції (13), фактично утворює $\mathrm{Cr}_{3} \mathrm{C}_{2}$, тому що реакції (2) i (7) обумовлять нестійкість $\mathrm{Cr}_{3} \mathrm{C}_{2}$, і слід замість (13) записати:

$$
1 / 3 \mathrm{Cr}_{2} \mathrm{O}_{3}+\mathrm{H}_{2}+4 / 7 \mathrm{CO}=2 / 21 \mathrm{Cr}_{7} \mathrm{C}_{3}+\mathrm{H}_{2} \mathrm{O}+2 / 7 \mathrm{CO}_{2}
$$


Таким чином, до основних реакцій комплексного відновлення оксиду хрому слід віднести (2), (3), (7) і (16), а також реакцію

$$
\mathrm{H}_{2} \mathrm{O}+\mathrm{CO}=\mathrm{H}_{2}+\mathrm{CO}_{2}
$$

Із зазначених реакцій лише три є незалежними. Як було встановлено раніше при відновленні $\mathrm{Cr}_{2} \mathrm{O}_{3}$ графітом відносно повільній лан-

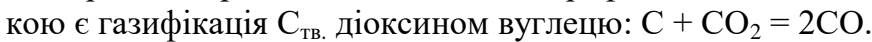

Газифікація вуглецю, пов'язаного в карбід, зустрічає ще більші труднощі, тому що реакції (2) i (7) можна вважати лимитуючими ланками. Решта реакції протікають відносно швидко і визначають склад газової фази в реакційному просторі.
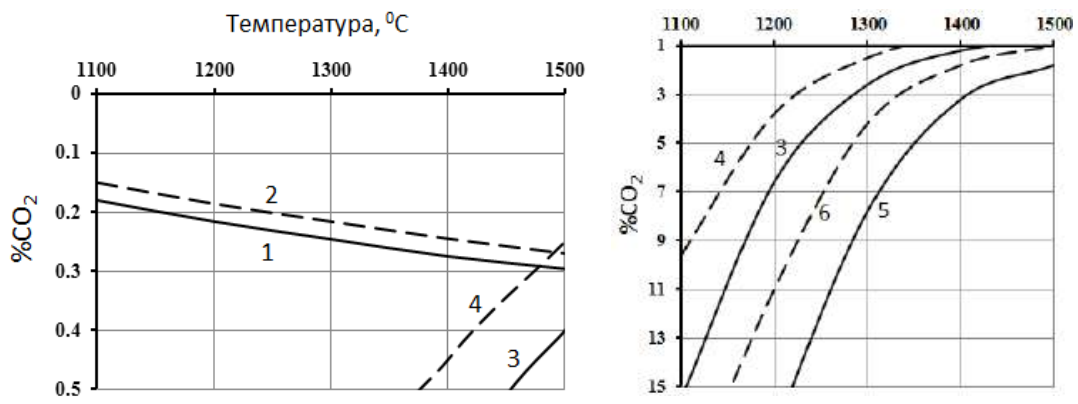

Рис. 3. Рівноважний склад газовий фази реакцій відновлення

$\mathrm{Cr}_{2} \mathrm{O}_{3}$ та утворення карбідів, при: 1 атм - 1,3,5; і 0,5 атм - 2,4,6.

$5,6-7 / 3 \mathrm{Cr}+2 \mathrm{CO}=1 / 3 \mathrm{Cr}_{7} \mathrm{C}_{3}+\mathrm{CO}_{2}$

\section{$1,2-1 / 3 \mathrm{Cr}_{2} \mathrm{O}_{3}+11 / 7 \mathrm{CO}=2 / 21 \mathrm{Cr}_{7} \mathrm{C}_{3}+9 / 7 \mathrm{CO}_{2} ; 3,4-$ $3 / 2 \mathrm{Cr}+2 \mathrm{CO}=1 / 2 \mathrm{Cr}_{3} \mathrm{C}_{2}+\mathrm{CO}_{2}$;}

3 опорою на викладене, був проведений термодинамічний аналіз комплексного відновлення $\mathrm{Cr}_{2} \mathrm{O}_{3}-$ карбідом $\mathrm{Cr}_{3} \mathrm{C}_{2}$ в потоці $\mathrm{H}_{2}$. Прийнято: $\mathrm{P}=\mathrm{P}_{\mathrm{H} 2}+\mathrm{P}_{\mathrm{H} 2 \mathrm{O}}+\mathrm{P}_{\mathrm{CO}}+\mathrm{P}_{\mathrm{CO} 2}=1$; при цьому $\mathrm{P}_{\mathrm{H} 2}+\mathrm{P}_{\mathrm{H} 2 \mathrm{O}}=\mathrm{P}_{\mathrm{CO}}+$ $\mathrm{P}_{\mathrm{CO} 2}=0,5$. Константа рівноваги реакції (17):

$$
\frac{\mathrm{P}_{\mathrm{H}_{2}}}{\mathrm{P}_{\mathrm{H}_{2} \mathrm{O}}}=\mathrm{K}_{24} \cdot \frac{\mathrm{P}_{\mathrm{CO}}}{\mathrm{P}_{\mathrm{CO}_{2}}}=\frac{0,5-\mathrm{P}_{\mathrm{H}_{2} \mathrm{O}}}{\mathrm{P}_{\mathrm{H}_{2} \mathrm{O}}} \text {, откуда следует } \mathrm{P}_{\mathrm{H}_{2} \mathrm{O}}=\frac{0,5}{1+\mathrm{K}_{24} \cdot \mathrm{P}_{\mathrm{CO}} / \mathrm{P}_{\mathrm{CO}_{2}}}
$$

Величини $\mathrm{P}_{\mathrm{CO}}$ i $\mathrm{P}_{\mathrm{CO} 2}$ відповідають рівноваги реакції (3) при тиску вуглецевовмістких газів 0,5 атм (0,05 МПа). Результати розрахунків дозволяють зробити висновок, що реакція (1) стає принципово можливою при $\sim 1250^{\circ} \mathrm{C}$. Зниження температури початку відновлення 
$\mathrm{Cr}_{2} \mathrm{O}_{3}$ карбідом $\mathrm{Cr}_{3} \mathrm{C}_{2}$ (див. рис. 1) цілком природно через розведення вуглецевовмістких газів сумішшю $\mathrm{H}_{2}-\mathrm{H}_{2} \mathrm{O}$. Водень входить в комплексне відновлення $\mathrm{Cr}_{2} \mathrm{O}_{3}$ ще раніше - при температурі $\sim 1130^{\circ} \mathrm{C}$. Таким чином існують термодинамічні передумови для інтенсифікації вилучення хрому з оксидних фаз за рахунок карбіду $\mathrm{Cr}_{3} \mathrm{C}_{2}$ за участю водню.

\title{
Література:
}

1. Туркдоган Е.Т. Физическая химия высокотемпературных процессов. Пер. с англ. - М. : Металлургия, 1985. - 344 с.

2. Острик П.Н. Металлургия губчатых и порошковых лигатур / Острик П.Н., Гасик М.М., Пирог В.Д. - К. : Техніка, 1992. - 128 с.

DOI https://doi.org/10.30525/978-9934-588-79-2-1.37

\section{RESEARCH OF THE UNLOADING OF CHARGE MATERIALS FROM THE CONE VALVE OF THE LOADING DEVICES OF THE BLAST FURNACE}

\author{
Selegej A. N. \\ Candidate of Technical Sciences, Associate Professor, \\ Associate Professor at the Department of Applied Mechanics \\ National Metallurgical Academy of Ukraine \\ Petrenko V. A. \\ Doctor of Technical Sciences, Professor, \\ Professor at the Intellectual Property Department \\ National Metallurgical Academy of Ukraine \\ Kvasova L. S. \\ Candidate of Technical Sciences, Associate Professor, \\ Associate Professor at the Department of Management \\ National Metallurgical Academy of Ukraine \\ Dnipro, Ukraine
}

The method for determining the parameters of the output of charge materials from the hoppers of the cone-free charging devices of blast furnaces can be used to calculate the consumption of charge materials when the conical charging device of the blast furnace leaves the large cone 